\title{
Leishmania (Mundinia) orientalis n. sp. (Trypanosomatidae), a parasite from Thailand responsible for localised cutaneous leishmaniasis
}

Narissara Jariyapan ${ }^{1 *}$, Teerada Daroontum² $^{2}$, Krit Jaiwong ${ }^{3}$, Wetpisit Chanmol ${ }^{1}$, Nuchpicha Intakhan ${ }^{1}$, Sriwatapron Sor-suwan ${ }^{4}$, Padet Siriyasatien ${ }^{4}$, Pradya Somboon ${ }^{1}$, Michelle D. Bates ${ }^{5}$ and Paul A. Bates ${ }^{{ }^{*}}$

\begin{abstract}
Background: Leishmaniasis is an emerging disease in Thailand with an unknown incidence or prevalence. Although the number of properly characterized and clinically confirmed cases is about 20, it is suspected that this low number masks a potentially high prevalence, with clinical disease typically manifesting itself against an immunocompromised background, but with a substantial number of subclinical or cured cases of infection. To date leishmaniasis in Thailand has been mainly ascribed to two taxa within the recently erected subgenus Mundinia Shaw, Camargo \& Teixeira, 2016, Leishmania (Mundinia) martiniquensis Desbois, Pratlong \& Dedet, 2014 and a species that has not been formally described prior to this study.

Results: A case of simple cutaneous leishmaniasis was diagnosed in a patient from Nan Province, Thailand. Molecular analysis of parasites derived from a biopsy sample revealed this to be a new species of Leishmania Ross, 1908, which has been named as Leishmania (Mundinia) orientalis Bates \& Jariyapan n. sp. A formal description is provided, and this new taxon supercedes some isolates from the invalid taxon "Leishmania siamensis". A summary of all known cases of leishmaniasis with a corrected species identification is provided.

Conclusions: Three species of parasites are now known to cause leishmaniasis is Thailand, L. martiniquensis and $L$. orientalis n. sp. in the subgenus Mundinia, which contains the type-species Leishmania enriettii Muniz \& Medina, 1948, and a single case of Leishmania infantum Nicolle, 1908. This study now enables epidemiological and other investigations into the biology of these unusual parasites to be conducted. It is recommended that the use of the taxonomically invalid name "L. siamensis" should be discontinued.
\end{abstract}

Keywords: Leishmania orientalis, Mundinia, Thailand, Cutaneous leishmaniasis

\section{Background}

Leishmaniasis is an emerging disease in Thailand. The first confirmed autochthonous case was reported in 1999 [1], but since then there have been further cases described that undoubtedly reflect a much higher underlying prevalence of undiagnosed cases and asymptomatic infections, given that no active case detection

\footnotetext{
* Correspondence: njariyapan@gmail.com; p.bates@lancaster.ac.uk

'Department of Parasitology, Faculty of Medicine, Chiang Mai University, Chiang Mai, Thailand

${ }^{5}$ Division of Biomedical and Life Sciences, Faculty of Health and Medicine, Lancaster University, Lancaster, UK

Full list of author information is available at the end of the article
}

study has been performed to date and there is little experience in diagnosis of leishmaniasis in Thailand. To date a total of 22 parasitologically confirmed cases have been reported, and of these 19 have been identified using various molecular methods. There has been one case of visceral leishmaniasis due to Leishmania infantum Nicolle, 1908 infection [2], but no subsequent reports.

The most frequent parasite found so far is L. martiniquensis Desbois, Pratlong \& Dedet, 2014, accounting for 15 of the identified cases. This parasite is named after the Caribbean island of Martinique, where it was

(c) The Author(s). 2018 Open Access This article is distributed under the terms of the Creative Commons Attribution 4.0 International License (http://creativecommons.org/licenses/by/4.0/), which permits unrestricted use, distribution, and 
first isolated [3, 4]. In some of the early Thailand reports this is referred to as "L. siamensis"; however, there are two problems with this usage. The first problem is that "L. siamensis" has never been formally described, so the name is taxonomically invalid (a nomen nudum), without any type specimen for reference, and therefore technically should not have been used in any publications. The second problem is subsequent evidence that the group of isolates that have previously been called "L. siamensis" has been found not to be monophyletic, and includes two taxa $[5,6]$. One of these includes the aforementioned parasites that appear identical to $L$. martiniquensis and, since this is a valid species, this name takes precedence for these particular isolates. However, in the second taxon there are two isolates of "L. siamensis" that are very similar to each other but different from L. martiniquensis based on molecular analysis, the PCM2 Trang strain from a patient in southern Thailand [7], which is phylogenetically distinct $[6,8]$, and a recent isolate from central Thailand [9]. These two isolates were both from patients that were HIV-infected and presented with disseminated cutaneous leishmaniasis, the former also with visceral disease.

Here we describe a case of simple cutaneous leishmaniasis from northern Thailand that was caused by a parasite apparently very similar to those responsible for these two previous cases, and we formally name this as Leishmania orientalis Bates \& Jariyapan n. sp., thereby establishing a taxonomically valid name for these parasites, and simultaneously eliminating the need to use the unavailable name "L. siamensis". We place this new species in the recently erected Leishmania subgenus Mundinia Shaw, Camargo \& Teixeira, 2016 [10] and provide an updated identification of all known previous isolates from Thailand into $L$. infantum, $L$. martiniquensis and L. orientalis n. sp.

\section{Results}

\section{Case report}

The patient was a 57-year-old woman who lives in Chiang Klang District, Nan Province, northern Thailand. She is a gardener and has never been abroad, only travelling to Phitsanulok and Phijit, provinces near Nan in Thailand. The patient presented in May 2014 at Chiang Klang Hospital with a single skin nodule on her left cheek $(1.0 \times 1.5$ $\mathrm{cm}$ ), and also with crusting at the left angle of the mouth (Fig. 1a). No skin nodules in other sites of the body were observed. Two pieces of formalin-fixed skin biopsy from the cheek nodule $\left(0.6 \times 0.5 \times 0.4 \mathrm{~cm}^{3}\right.$ and $0.5 \times 0.5 \times 0.2$ $\mathrm{cm}^{3}$ ) were sent to the Department of Pathology, Faculty of Medicine, Chiang Mai University for histopathological investigation. Histopathological analyses revealed epidermal ulceration with a heavy, chronic inflammation of the dermis (Fig. 2a) and numerous intracellular small round or oval-shaped bodies, with the appearance of amastigotes (1-2 $\mu \mathrm{m}$ in width and $2-4 \mu \mathrm{m}$ in length) of Leishmania spp. (Fig. 2b). A week later, a fresh skin biopsy from the nodule $\left(0.4 \times 0.5 \times 0.3 \mathrm{~cm}^{3}\right)$ was collected and sent to Department of Parasitology, Faculty of Medicine, Chiang Mai University for confirmation of diagnosis by parasite culture and species identification. The skin biopsy sample was cultured in Schneider's insect medium supplemented with $20 \%$ foetal bovine serum (FBS) and 50 International Units penicillin $/ \mathrm{ml}, 50 \mu \mathrm{g} / \mathrm{ml}$ streptomycin at $25^{\circ} \mathrm{C}$. Motile promastigotes were first observed on day 3 of the culture. Therefore, the patient was confirmed as diagnosed with cutaneous leishmaniasis. She was treated with oral amphotericin B at $1 \mathrm{mg} / \mathrm{kg} /$ day for 1 day and fluconazole at $200 \mathrm{mg} /$ day for 45 days. The skin lesion had disappeared completely by six months after treatment (Fig. 1b). Pre-treatment laboratory investigation showed only mild anaemia with a haemoglobin concentration of $10.9 \mathrm{~g} / \mathrm{dl}$, white blood count of 7700 cells $/ \mathrm{mm}^{3}$, and platelet count of $483,000 / \mathrm{mm}^{3}$. There was no hepatosplenomegaly or

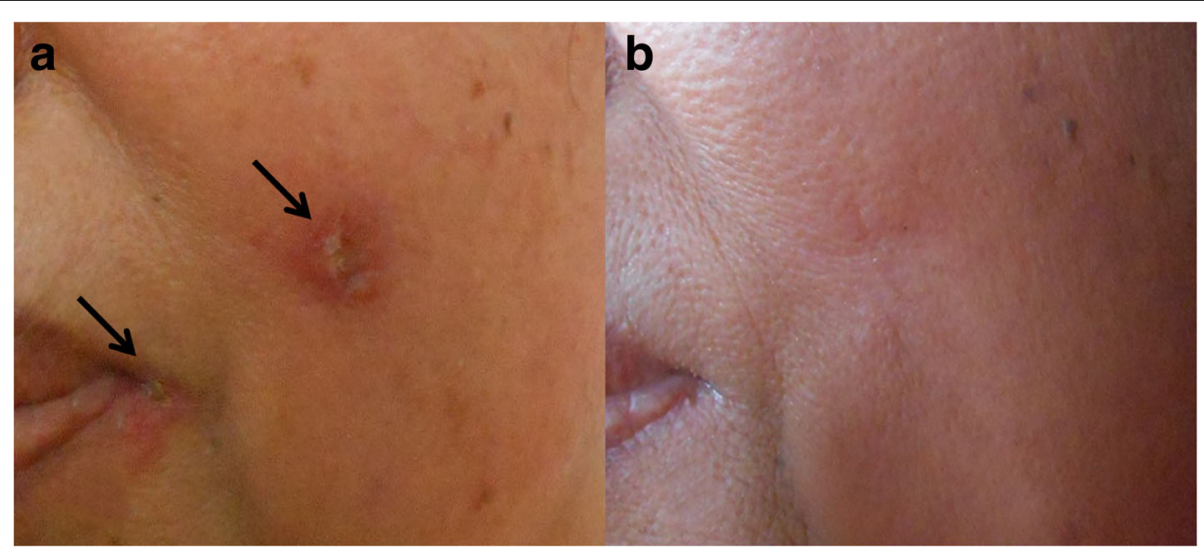

Fig. 1 Clinical presentation of cutaneous leishmaniasis. a A nodule on the cheek and a crusted sore in the angle of the lips of the patient before treatment, both arrowed. $\mathbf{b}$ The same view of the patient's skin after treatment 

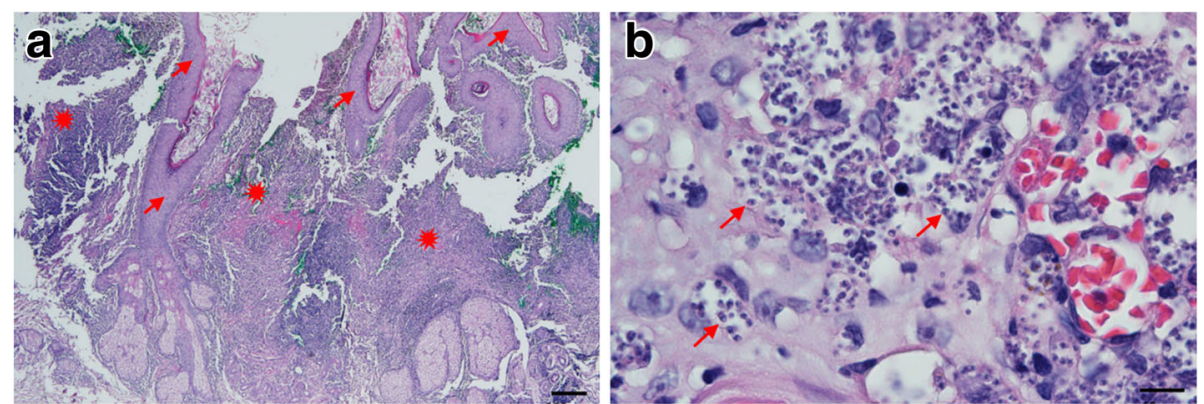

Fig. 2 Histopathology of skin biopsy from a nodule on the left cheek (Giemsa stain). a Low power magnification photomicrograph showing pseudo-epitheliomatous hyperplasia of the epidermis (arrows) and heavy chronic inflammation of dermis (starbursts). b High power magnification photomicrograph showing numerous Leishmania amastigotes within the cytoplasm of macrophages and in the extracellular matrix (arrows). Scale-bars: $\mathbf{a}, 200 \mu \mathrm{m} ; \mathbf{b}, 10 \mu \mathrm{m}$

palpable lymph nodes. Liver function was not investigated, renal function was within normal limits and HIV serology was negative. The patient declined a bone marrow biopsy for evaluation of visceral leishmaniasis. She did not report any other underlying disease, routine drug use, or any other symptoms, and in general was in a good state of health.

\section{Parasite characterization}

The patient isolate has the World Health Organisation strain designation MHOM/TH/2014/LSCM4, hereafter referred to as CM4. Promastigote cultures were established by a serial sub-passage from the initial culture using liquid media, and their morphology examined by light microscopy of Giemsa-stained slides (Fig. 3). The morphological forms observed were generally similar to those described for other Leishmania species, demonstrating a range of promastigote types, and including some similar to procyclic promastigotes, leptomonad promastigotes, nectomonad promastigotes and metacyclic promastigotes
[11]. Although free-swimming individual promastigotes were readily observed, rosettes and large aggregates of promastigotes were prevalent in culture (Additional file 1: Video S1).

\section{Molecular analysis}

Four different sequences were analysed by polymerase chain reaction (PCR) and deoxyribonucleic acid (DNA) sequencing: the ribosomal ribonucleic acid (RNA) internal transcribed spacer 1 (ITS1) [12]; the ribosomal protein L23a intergenic sequence (RPL23a) [13]; the large subunit of RNA Polymerase II (RNA PolII) [14]; and heat-shock protein 70 (HSP70) [15]. The accession numbers for the new sequences generated in this study together with others used in the following analyses are given in Additional file 2: Table S1. Initial Basic Local Alignment Search Tool analysis revealed the CM4 sequences to be closest to PCM2 Trang [7] and/or the related isolate from central Thailand [9] for all four sequences examined, and
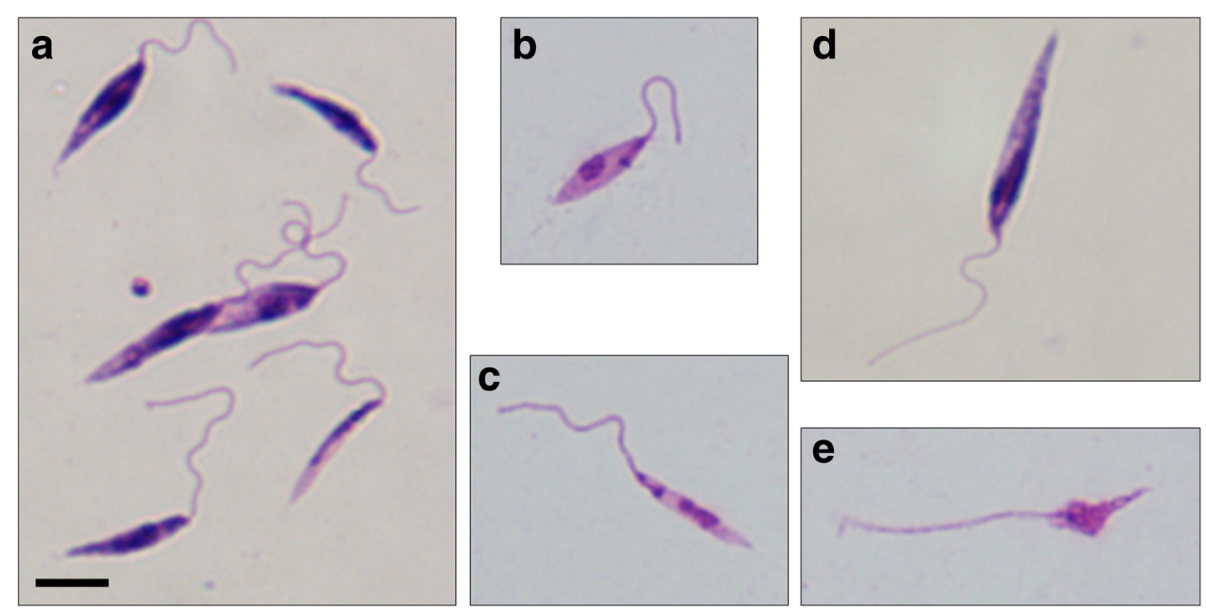

Fig. 3 Morphology of Giemsa-stained promastigote forms from culture showing morphological variation of forms observed (a); procyclic-like promastigote (b); leptomonad-like promastigote $(\mathbf{c})$; nectomonad-like promastigote (d); and metacyclic-like promastigote (e). All images are at the same magnification. Scale-bar: 5 um 
then to other members of the subgenus Leishmania (Mundinia) (Fig. 4). In three of the analyses the CM4 clade was closest to that containing the recently described (but not yet named) parasites from Ghana [8], and in the RNA PolII tree appeared equidistant between these and L. enriettii. In all phylogenetic analyses the CM4 clade (labelled L. orientalis in Fig. 4) is clearly distinct from the L. martiniquensis clade that also contains several Thai isolates. The sequences of CM4 and PCM2 Trang were very similar to each other or identical in all cases (Table 1), whereas CM4 and a Thai isolate of L. martiniquensis called CM1 [6] were different (Table 2).

\section{Taxonomic description}

Class Kinetoplastea Honigberg, 1963

Order Trypanosomatida Kent, 1880

Family Trypanosomatidae Doflein, 1951

Genus Leishmania Ross, 1903

Subgenus L. (Mundinia) Shaw, Camargo \& Teixeira 2016

Leishmania (Mundinia) orientalis Bates \& Jariyapan n. sp.

Type-host: Homo sapiens.




Table 1 Comparisons of LSCM4 DNA sequences with those from PCM2 Trang [7]. The lengths of the sequences given are the number of nucleotides, the analysis excludes PCR primers and comparisons were made using Clustal Omega

\begin{tabular}{|c|c|c|c|c|c|}
\hline Sequence & Length LSCM4 & Length PCM2 & $\%$ identity $^{a}$ & No. of identical nt & No. of differences \\
\hline ITS-1 & 251 & 251 & 96.4 & 242 & 9 \\
\hline RPL23a IGS & 468 & 468 & 99.4 & 465 & 3 \\
\hline RNAPoIII & 1206 & 1206 & 100 & 1206 & 0 \\
\hline HSP70 & 1319 & 1319 & 100 & 1319 & 0 \\
\hline
\end{tabular}

${ }^{a} \%$ identity $=$ no. of identical nucleotides/longest length, where sequence length differs

Type-locality: Chiang Klang District $\left(19^{\circ} 17^{\prime} 30^{\prime \prime} \mathrm{N}, 100^{\circ}\right.$ 51'42"E), Nan Province, Thailand.

Type-material: Hapantotypes, cryopreserved promastigotes stored in liquid nitrogen at the Department of Parasitology, Chiang Mai University, Thailand (accession LSCM4) and the Division of Biomedical and Life Sciences, Lancaster University, UK (accession LV768).

Strain designation: MHOM/TH/2014/LSCM4.

Homologous strains: PCM2 Trang [7] and an unnamed isolate from central Thailand [9].

Vector: Unknown.

Reservoir(s): Unknown.

Representative DNA sequences: The RNA internal transcribed spacer 1, ribosomal protein L23a intergenic sequence, partial large subunit of RNA Polymerase II and partial heat-shock protein 70 sequences were deposited in the GenBank database under the accession numbers MG731227, MG731231, MG731232 and MG731233, respectively.

ZooBank registration: To comply with the regulations set out in article 8.5 of the amended 2012 version of the International Code of Zoological Nomenclature (ICZN) [16], details of the new species have been submitted to ZooBank. The Life Science Identifier (LSID) of the article is urn:lsid: zoobank.org:pub:6C6CBD86-4C7A-437E-B4C7-B6229C9F6 C67. The LSID for the new name Leishmania orientalis is urn:lsid:zoobank.org:act:C03ADE08-34BD-4252-A534-831D 57A3A8D9.

Etymology: Species name refers to eastern origin since this parasite is unlikely to be confined to Thailand only.

\section{Description (Figs. 2, 3)}

Morphology. Amastigotes 1-2 $\mu \mathrm{m}$ in width and 2-4 $\mu \mathrm{m}$ in length. Promastigotes of various sizes with body length ranging between $5-15 \mu \mathrm{m}$ and motile with a free anterior flagellum of variable length.

Growth in vitro. Isolated in Schneider's Drosophila medium supplemented with 20\% (v/v) FBS and maintained in the same medium or Medium 199 supplemented with 10\% (v/v) FBS and Basal Medium Eagle (BME) vitamins. Relatively easy to grow compared to other Leishmania species by subpassage every 1-2 weeks.

Pathology. Variable; in the type-host presentation was cutaneous leishmaniasis with no known underlying immunodeficiency; in other strains presentation as disseminated cutaneous leishmaniasis, with possible visceral disease, both in the presence of human immunodeficiency virus (HIV) co-infection.

\section{Remarks}

The new species was characterized using molecular techniques, revealing a distinct parasite within the subgenus Mundinia. Two isolates, PCM2 Trang [7] and an unnamed isolate from central Thailand [9] are considered as being L. (M.) orientalis due to their high level of similarity with the type-strain LSCM4.

\section{Discussion}

Here we describe a new species of Leishmania causing human disease in Thailand, Leishmania orientalis. Together with L. martiniquensis the new species accounts for almost all of the known cases of leishmaniasis reported in Thailand (Table 3). The only exception is one case of L. infantum reported in 2008 [2], but in that case it was suspected the infection may have been acquired elsewhere.

Table 2 Comparisons of LSCM4 DNA sequences with those from L. martiniquensis LSCM1 [6]. The lengths of the sequences given are the number of nucleotides, the analysis excludes PCR primers and comparisons were made using Clustal Omega

\begin{tabular}{|c|c|c|c|c|c|}
\hline Sequence & Length LSCM4 & Length LSCM1 & $\%$ identity $^{a}$ & No. of identical nt & No. of differences \\
\hline ITS1 & 251 & 259 & 59.1 & 153 & 106 \\
\hline RPL23a IGS & 468 & 472 & 64.8 & 306 & 166 \\
\hline RNAPolll & 1206 & 1206 & 91.5 & 1104 & 102 \\
\hline HSP70 & 1319 & 1319 & 95.7 & 1262 & 57 \\
\hline
\end{tabular}

${ }^{\mathrm{a}} \%$ identity $=$ no. of identical nucleotides/longest length, where sequence length differs 
Table 3 Reports of leishmaniasis from Thailand and Myanmar ordered by year of isolation. Where done, identification was performed by sequencing one or more DNA targets. Those identified with ${ }^{a}$ were originally or subsequently reported as "L. siamensis" but later identified to be L. martiniquensis by Pothirat et al. [6]. Those identified with ${ }^{\mathrm{b}}$ were originally reported as "L. siamensis" but shown in this study to be very similar to L. orientalis

\begin{tabular}{|c|c|c|c|c|c|c|c|}
\hline Year & Location & Age & Sex & HIV & Primary clinical presentation & Species identification & Reference \\
\hline 1996 & Surat Thani, Thailand & 3 & Female & No & Visceral leishmaniasis & Unknown & Thisyakorn et al. (1999) [1] \\
\hline 2005 & Nan, Thailand & 40 & Male & No & Visceral leishmaniasis & Unknown & Kongkaew et al. (2007) [35] \\
\hline 2006 & Phang-Nga, Thailand & 55 & Male & No & Visceral leishmaniasis & L. martiniquensis ${ }^{\mathrm{a}}$ & Sukmee et al. (2008) [36] \\
\hline 2007 & Bangkok, Thailand & 66 & Male & No & Visceral leishmaniasis & L. infantum & Maharom et al. (2008) [2] \\
\hline 2009 & Chantaburi, Thailand & 37 & Male & Yes & Visceral leishmaniasis & L. martiniquensis $^{\mathrm{a}}$ & Suankratay et al. (2010) [37] \\
\hline 2010 & Trang, Thailand & 35 & Female & Yes & $\begin{array}{l}\text { Disseminated cutaneous and visceral } \\
\text { leishmaniasis }\end{array}$ & L. orientalis ${ }^{\mathrm{b}}$ & Bualert et al. (2012) [7] \\
\hline 2010 & Satun, Thailand & 7 & Female & No & Visceral leishmaniasis & L. martiniquensis $^{\mathrm{a}}$ & Osatakul et al. (2014) [38] \\
\hline 2011 & Songkhla, Thailand & 46 & Male & Yes & Visceral and cutaneous leishmaniasis & L. martiniquensis $^{\mathrm{a}}$ & Chusri et al. (2012) [39] \\
\hline 2011 & Trang, Thailand & 30 & Male & Yes & Disseminated cutaneous leishmaniasis & L. martiniquensis $^{\mathrm{a}}$ & Chusri et al. (2012) [39] \\
\hline 2011 & Lop Buri, Thailand & 3 & Female & No & Cutaneous leishmaniasis & Unknown & $\begin{array}{l}\text { Kattipathanapong et al. } \\
\text { (2012) [40] }\end{array}$ \\
\hline 2012 & Yangon, Myanmar & 22 & Female & No & Asymptomatic & L. martiniquensis $^{\mathrm{a}}$ & Phumee et al. (2013) [41] \\
\hline 2012 & Chiang Rai, Thailand & 45 & Male & Yes & Disseminated cutaneous leishmaniasis & L. martiniquensis $^{\mathrm{a}}$ & Phumee et al. (2013) [41] \\
\hline 2012 & Yangon, Myanmar & 34 & Male & Yes & Disseminated cutaneous leishmaniasis & L. martiniquensis ${ }^{\mathrm{a}}$ & Phumee et al. (2013) [41] \\
\hline 2012 & Yangon, Myanmar & 60 & Male & No & Disseminated cutaneous leishmaniasis & L. martiniquensis ${ }^{\mathrm{a}}$ & Noppakun et al. (2014) [42] \\
\hline 2012 & Ban Thi, Thailand & 52 & Male & No & Visceral leishmaniasis & L. martiniquensis & Pothirat et al. (2014) [6] \\
\hline 2013 & Hang Dong, Thailand & 48 & Male & Yes & Disseminated cutaneous leishmaniasis & L. martiniquensis & Chiewchanvit et al. (2015) [33] \\
\hline 2013 & Mae Tha, Thailand & 38 & Male & Yes & Disseminated cutaneous leishmaniasis & L. martiniquensis & Chiewchanvit et al. (2015) [33] \\
\hline 2014 & Chiang Klang, Thailand & 57 & Female & No & Cutaneous leishmaniasis & L. orientalis & Present study \\
\hline 2017 & Kanchanaburi, Thailand & 42 & Female & Yes & Disseminated cutaneous leishmaniasis & L. orientalis $^{\mathrm{b}}$ & Supsrisunjai et al. (2017) [9] \\
\hline
\end{tabular}

Both L. orientalis and L. martiniquensis are members of the recently described Leishmania subgenus Mundinia, with the type-species $L$. enriettii $[10,17]$. Until recently, this was known as the $L$. enriettii species complex [6, 8, 18-20], but based largely on molecular data these species have emerged as a distinct monophyletic clade. Regarding human pathogenicity, the three other subgenera of Leishmania apart from Mundinia are relatively uniform, with $L$. (Leishmania) (type-species $L$. donovani Laveran \& Mesnil, 1903) and L. (Viannia) (type-species L. braziliensis Vianna, 1911) containing mainly human-infective species (with one or two exceptions), whereas the L. (Sauroleishmania) have never been found in humans - the so-called lizard Leishmania. In that respect the known members of Mundinia, to which we now add $L$. orientalis n. sp., present a rather eclectic mixture: three species are human pathogens, L. martiniquensis, L. orientalis n. sp. and Leishmania species Ghana; and two species are non-pathogenic to humans, L. enriettii, known to infect domestic guinea pigs in Brazil [21, 22], and L. macropodum Barratt, Kaufer \& Ellis, 2017, known to infect certain species of kangaroo and other macropods in Australia [23, 24]. The two other clades closest to L. orientalis n. sp. are L. enriettii and Leishmania species Ghana. From its known features L. enriettii is clearly different from L. orientalis, and also, given the differences in clinical presentation [8] and the results of the current and previous molecular analyses [8], Leishmania species Ghana also appears to be different from $L$. orientalis. Overall the diversity of hosts and variation in human pathogenicity of the species of Mundinia is most likely a reflection of their basal position in Leishmania phylogeny $[8,25]$. This diversity also supports a supercontinental origin of the subgenus, in which the Mundinia appeared before the other subgenera and prior to the breakup of Gondwana. This explains its presence in different continents and mammalian orders.

The vectors of the species of Leishmania (Mundinia) are not known with certainty, including efforts to incriminate sand flies, the normal vectors of leishmaniasis, although Lutzomyia monticola has been suggested as a possible vector for $L$. enriettii [26]. The best evidence is for $L$. macropodum, where unusually the vector appears to be a day-biting midge of the genus Forcipomyia [13]. Crucially these midges supported the development of infections beyond the blood meal stage and produced material similar to promastigote secretory gel and metacyclic promastigotes (infective stages). In addition, $L$. 
macropodum and L. enriettii can both develop beyond the blood meal in the experimental midge host Culicoides sonorensis Wirth \& Jones, 1957, whereas neither can establish in the normally permissive sand fly host Lutzomyia longipalpis Lutz \& Neiva, 1912 [27]. In contrast, Leishmania species in other subgenera show full development in Lu. longipalpis [28]. On the other hand, in Thailand there have been reports of Leishmania DNA in Sergentomyia sand flies [29, 30], suggesting the possible involvement of a new sand fly genus in transmission to humans, which would usually be a species of Phlebotomus in Asia. However, dissections were not performed to investigate whether these flies supported infection beyond the blood meal stage, which is required for transmission [31].

The recent emergence of leishmaniasis in Thailand is a worrying development, as there is little experience amongst clinicians and public health professionals in diagnosis, treatment or disease control in the country. This is compounded by the nature of the parasites themselves, which are two novel and therefore poorly understood species, $L$. martiniquensis and $L$. orientalis $\mathrm{n}$. sp. and preliminary evidence suggesting that they may have a different type of vector to that normally associated with transmission. The underlying rate of infection is almost certainly much higher than the number of case reports indicates, and could conceivably be a common but sub-clinical infection in most infected individuals, only manifesting when patients become immunocompromised in some way. In a recent study, the prevalence of Leishmania infection in a cohort of HIV patients from Trang Province, Thailand was 25.1\% [32]. Whilst these data may not be representative of the whole country, they clearly demonstrate the potential for a high underlying rate of exposure to Leishmania spp. in the general population. Clearly more work is required both on the basic biology and vectors of these species, as well as epidemiological investigation of the prevalence and incidence of infection in the human population.

\section{Methods}

\section{Parasite culture and morphology}

Promastigote cultures were obtained by inoculation of patient biopsy material into $5 \mathrm{ml}$ of Schneider's Drosophila medium (Sigma-Aldrich, St Louis, MO, USA) supplemented with 20\% (v/v) FBS (Thermo-Fisher, Waltham, MA, USA) in a $25-\mathrm{cm}^{2}$ tissue culture flask and maintained at $26{ }^{\circ} \mathrm{C}$ (Pothirat et al. [6]). Subsequently, promastigotes were passaged in the same medium, and also into Medium 199 (Lonza, Basel, Switzerland) supplemented with $10 \%(\mathrm{v} / \mathrm{v})$ FBS, BME vitamins (Sigma-Aldrich) and $25 \mu \mathrm{g} / \mathrm{ml}$ gentamicin sulphate (Sigma-Aldrich) for long term maintenance. Promastigotes were cryopreserved in $7.5 \%(\mathrm{v} / \mathrm{v})$ glycerol, $50 \%(\mathrm{v} / \mathrm{v})$ fetal bovine serum in culture medium and stored in liquid nitrogen. For morphological characterization, the culture parasites were smeared on microscope slides, air-dried, and fixed with absolute methanol. The samples were stained with Giemsa (1:10 in phosphate buffered distilled water, $\mathrm{pH}$ 6.8) for $30 \mathrm{~min}$, washed in running water, and drained dry. All sample slides were observed for Leishmania parasites under a light microscope at $1000 \times$ magnification using an oil immersion lens.

\section{Histology}

Skin samples were biopsied from a nodule of the left cheek of the patient, subsequently fixed in $10 \%$ formaldehyde and then sent to the Department of Pathology, Faculty of Medicine, Chiang Mai University. After processing, paraffin-embedded tissue sections of $5 \mu \mathrm{m}$ thickness were cut and stained with standard haematoxylin-eosin (H\&E). All sample slides were observed for general features and Leishmania parasites under a light microscope at 400x (dry lens) and 1000× (oil immersion lens), respectively.

\section{PCR and DNA sequencing}

PCR amplification of the ribosomal spacer ITS1 was performed with LeF/LeR primers[12], the RPL23a gene with BN1/BN2 primers [33], the RNA PolII gene with S1/S2 and S3/S4 primers [6], and the HSP70 gene with HSP70sen/HSP70ant primers [15], as previously described. Control DNA was from L. infantum (MCAN/ES/ 98/LEM-935;JPC;M5), which was used as an outgroup in the phylogenetic analyses. Twelve new sequences were generated as indicated in Additional file 2: Table S1. Amplification was performed with proof-reading DNA polymerase (Qiagen HotStar HiFidelity Polymerase) and products directly sequenced using commercial services. Results were checked for quality using Chromas Lite 2.1.1 (http://technelysium.com.au/).

\section{DNA sequence analysis}

Initial alignments and analyses were performed using Clustal Omega (http://www.ebi.ac.uk/Tools/msa/clustalo/). For phylogenetic analysis, alignment and tree building programmes in Molecular Evolutionary Genetics Analysis (MEGA) version 7 were used [34]. For ITS1 sequences the Kimura 2-parameter model (Invariant) gave the best-fitting model of sequence evolution and was used for tree construction using the maximum likelihood (ML) and neighbour-joining (NJ) methods. For the RPL23a sequences the Kimura 2-parameter model, for the large subunit of RNA polymerase II the Tamura-Nei (Gamma) model, and for the HSP70 the Hasegawa-Kishino-Yano (Gamma) model were used for tree construction using the ML and $\mathrm{NJ}$ methods. Bootstrapping was performed on all trees with 1000 replicates. 


\section{Additional files}

Additional file 1: Video S1. Live Leishmania orientalis promastigotes in vitro, illustrating both free-swimming and aggregations of promastigotes. (WMV $28731 \mathrm{~kb}$ )

Additional file 2: Table S1. Accession numbers for sequences analysed in this study. New sequences are indicated by *. (DOCX $15 \mathrm{~kb}$ )

\section{Abbreviations \\ BME: Basal Medium Eagle; DNA: Deoxyribonucleic acid; FBS: Foetal bovine serum; H\&E: Haematoxylin-eosin; HIV: Human immunodeficiency virus; HSP70: Heat-shock protein 70; ITS1: Internal transcribed spacer 1; MEGA: Molecular Evolutionary Genetics Analysis; ML: Maximum likelihood NJ: Neighbour-joining; PCR: Polymerase chain reaction; RNA Polll: Large subunit of RNA Polymerase II; RNA: Ribonucleic acid; RPL23a: Ribosomal protein $\mathrm{L} 23 \mathrm{a}$ intergenic sequence}

\section{Acknowledgements}

We thank Associate Professor Dr Nimit Morakote and Associate Professor Dr Atchariya Jitpakdi for technical help and Professor Dr Saovanee Leelayoova for providing us with genomic DNA of Leishmania PCM2 Trang strain.

\section{Funding}

This work was supported by the Diamond Research Grant, Faculty of Medicine, Chiang Mai University, Thailand and by the Faculty of Health and Medicine, Lancaster University, UK. The funders had no role in study design, data collection and analysis, decision to publish, or preparation of the manuscript.

\section{Availability of data and materials}

The data supporting the conclusions of this article are included within the article and its additional files. The newly generated sequences were submitted to the GenBank/EBI/DDBJ under the accession numbers MG731227-MG731238. Leishmania orientalis type-material is available from the authors upon request. The type-material was deposited at the Department of Parasitology, Chiang Mai University, Thailand (accession LSCM4) and Division of Biomedical and Life Sciences, Lancaster University, UK (accession LV768).

\section{Authors' contributions}

$\mathrm{NJ}$ and PAB conceived and designed the experiments. TD and $\mathrm{KJ}$ took care of the patient. NJ, WC, NI, SS and MDB performed the experiments. NJ, PSi, PSo and PAB analyzed the data. NJ, TD and PAB wrote the paper. All authors read and approved the final manuscript.

\section{Ethics approval and consent to participate}

The patient described in this report was treated at Nan hospital, northern Thailand for a skin lesion. All biopsies and other clinical investigations on the patient were performed with consent as part of routine clinical investigations to determine the nature of the condition. No samples or procedures were undertaken for research purposes only. This report does not contain any information that could be used to compromise patient confidentiality.

\section{Consent for publication}

Consent to publish the details described in this report has been provided by the patient.

\section{Competing interests}

The authors declare that they have no competing interests.

\section{Publisher's Note}

Springer Nature remains neutral with regard to jurisdictional claims in published maps and institutional affiliations.

\section{Author details}

'Department of Parasitology, Faculty of Medicine, Chiang Mai University, Chiang Mai, Thailand. 'Department of Pathology, Faculty of Medicine, Chiang Mai University, Chiang Mai, Thailand. ${ }^{3}$ Santisuk Hospital, Santisuk, Nan, Thailand. ${ }^{4}$ Department of Parasitology, Faculty of Medicine, Chulalongkorn University, Bangkok, Thailand. ${ }^{5}$ Division of Biomedical and Life Sciences, Faculty of Health and Medicine, Lancaster University, Lancaster, UK.
Received: 4 January 2018 Accepted: 21 May 2018

Published online: 18 June 2018

\section{References}

1. Thisyakorn U, Jongwutiwes S, Vanichsetakul P, Lertsapcharoen P. Visceral leishmaniasis: the first indigenous case report in Thailand. Trans R Soc Trop Med Hyg. 1999;93:23-4.

2. Maharom P, Siripattanapipong S, Mungthin M, Naaglor T, Sukkawee R, Pudkorn $\mathrm{R}$, et al. Visceral leishmaniasis caused by Leishmania infantum in Thailand. Southeast Asian J Trop Med Public Health. 2008;39:988-90.

3. Dedet JP, Roche B, Pratlong F, Cales-Quist D, Jouannelle J, Benichou JC, Huerre M. Diffuse cutaneous infection caused by a presumed monoxenous trypanosomatid in a patient infected with HIV. Trans R Soc Trop Med Hyg. 1995:89:644-6.

4. Desbois N, Pratlong F, Quist D, Dedet JP. Leishmania (Leishmania) martiniquensis n. sp. (Kinetoplastida: Trypanosomatidae), description of the parasite responsible for cutaneous leishmaniasis in Martinique Island (French West Indies). Parasite. 2014;21:12.

5. Leelayoova S, Siripattanapipong S, Hitakarun A, Kato H, Tan-ariya P, Siriyasatien $\mathrm{P}$, et al. Multilocus characterization and phylogenetic analysis of Leishmania siamensis isolated from autochthonous visceral leishmaniasis cases, southern Thailand. BMC Microbiol. 2013;13:60.

6. Pothirat T, Tantiworawit A, Chaiwarith $R$, Jariyapan N, Wannasan A Siriyasatien $\mathrm{P}$, et al. First record of leishmaniasis in northern Thailand: case report, identification as Leishmania martiniquensis and phylogenetic position within the Leishmania enriettii complex. PLOS Negl Trop Dis. 2014;8:e3339.

7. Bualert L, Charungkiattikul W, Thongsuksai P, Mungthin M, Siripattanapipong S, Khositnithikul R, et al. Autochthonous disseminated dermal and visceral leishmaniasis in an AIDS patient, southern Thailand, caused by Leishmania siamensis. Am J Trop Med Hyg. 2012;86:821-4.

8. Kwakye-Nuako G, Mosore MT, Duplessis C, Bates MD, Puplampu N, MensahAttipoe I, et al. First isolation of a new species of Leishmania responsible for human cutaneous leishmaniasis in Ghana and classification in the Leishmania enriettii complex. Int J Parasitol. 2015:45:679-84.

9. Supsrisunjai $C$, Kootiratrakarn T, Puangpet $P$, Bunnag T, Chaowalit $P$, Wessagowit $\mathrm{V}$. Disseminated autochthonous dermal leishmaniasis caused by Leishmania siamensis (PCM2 Trang) in a patient from central Thailand infected with human immunodeficiency virus. Am J Trop Med Hyg. 2017:96:1160-3.

10. Espinosa OA, Serrano MG, Camargo EP, Teixeira MM, Shaw JJ. An appraisal of the taxonomy and nomenclature of trypanosomatids presently classified as Leishmania and Endotrypanum. Parasitology. 2016;15:1-13.

11. Rogers ME, Chance ML, Bates PA. The role of promastigote secretory gel in the origin and transmission of the infective stage of Leishmania mexicana by the sand fly Lutzomyia longipalpis. Parasitology. 2002;124:495-508.

12. Spanakos G, Piperaki ET, Menounos PG, Tegos N, Flemetakis A, Vakalis NC Detection and species identification of Old World Leishmania in clinical samples using a PCR-based method. Trans R Soc Trop Med Hyg. 2008;102:46-53.

13. Dougall AM, Alexander B, Holt DC, Harris T, Sultan AH, Bates PA, et al. Evidence incriminating midges (Diptera: Ceratopogonidae) as potential vectors of Leishmania in Australia. Int J Parasitol. 2011:41:571-9.

14. Croan DG, Morrison DA, Ellis JT. Evolution of the genus Leishmania revealed by comparison of DNA and RNA polymerase gene sequences. Mol Biochem Parasitol. 1997;89:149-59.

15. Garcia L, Kindt A, Bermudez H, Llanos-Cuentas A, De Doncker S, Arevalo J, et al. Culture-independent species typing of neotropical Leishmania for clinical validation of a PCR-based assay targeting heat shock protein 70 genes. J Clin Microbiol. 2004;42:2294-7.

16. ICZN. International Commission on Zoological Nomenclature: Amendment of articles 8, 9, 10, 21 and 78 of the International Code of Zoological Nomenclature to expand and refine methods of publication. Bull Zool Nomencl. 2012:69:161-9.

17. Paranaiba LF, Pinheiro LJ, Macedo DH, Menezes-Neto A, Torrecilhas AC, Tafuri WL, Soares RP. An overview on Leishmania (Mundinia) enriettii: biology, immunopathology, LRV and extracellular vesicles during the hostparasite interaction. Parasitology. 2017;10:1-9.

18. Akhoundi M, Kuhls K, Cannet A, Votýpka J, Marty P, Delaunay P, Sereno D. A historical overview of the classification, evolution, and dispersion of Leishmania parasites and sand flies. PLoS Negl Trop Dis. 2016;10:e0004349.

19. Paranaiba LF, Pinheiro LJ, Torrecilhas AC, Macedo DH, Menezes-Neto A, Tafuri WL, Soares RP. Leishmania enriettii (Muniz \& Medina, 1948): A highly diverse parasite is here to stay. PLoS Pathog. 2017;13:e1006303.

20. Cotton JA. The expanding world of human leishmaniasis. Trends Parasitol. 2017:33:341-4. 
21. Muniz J, Medina H. Cutaneous leishmaniasis of the guinea pig, Leishmania enriettii n. sp. Hospital (Rio J). 1948:33:7-25.

22. Machado MI, Milder RV, Pacheco RS, Silva M, Braga RR, Lainson R. Naturally acquired infections with Leishmania enriettii Muniz and Medina 1948 in guinea-pigs from São Paulo. Brazil. Parasitology. 1994;109:135-8.

23. Dougall A, Shilton C, Low Choy J, Alexander B, Walton S. New reports of Australian cutaneous leishmaniasis in Northern Australian macropods. Epidemiol Infect. 2009;137:1516-20.

24. Barratt J, Kaufer A, Peters B, Craig D, Lawrence A, Roberts T, et al. Isolation of novel trypanosomatid, Zelonia australiensis sp. nov. (Kinetoplastida: Trypanosomatidae) provides support for a Gondwanan origin of dixenous parasitism in the Leishmaniinae. PLoS Negl Trop Dis. 2017;11:e0005215.

25. Harkins KM, Schwartz RS, Cartwright RA, Stone AC. Phylogenomic reconstruction supports supercontinent origins for Leishmania. Infect Genet Evol. 2016;38:101-9.

26. Luz E, Giovannoni M, Borba A. Infeccão de Lutzomyia monticola por Leishmania enriettii. An Fac Med Univ Fed Parana. 1967;9:121-8.

27. Šeblová V, Sádlová J, Vojtková B, Votýpka J, Carpenter S, Bates PA, Volf P. The biting midge Culicoides sonorensis (Diptera: Ceratopogonidae) is capable of developing late stage infections of Leishmania enriettii. PLoS Negl Trop Dis. 2015;9:e0004060.

28. Dostálová A, Volf P. Leishmania development in sand flies: parasite-vector interactions overview. Parasit Vectors. 2012;5:276

29. Kanjanopas K, Siripattanapipong S, Ninsaeng U, Hitakarun A, Jitkaew S, Kaewtaphaya P, et al. Sergentomyia (Neophlebotomus) gemmea, a potential vector of Leishmania siamensis in southern Thailand. BMC Infect Dis. 2013;13:333.

30. Chusri S, Thammapalo S, Chusri S, Thammapalo S, Silpapojakul K, Siriyasatien P. Animal reservoirs and potential vectors of Leishmania siamensis in southern Thailand. Southeast Asian J Trop Med Public Health. 2014;45:13-9.

31. Ready P. Biology of phlebotomine sand flies as vectors of disease agents. Annu Rev Entomol. 2013;58:227-50.

32. Manomat J, Leelayoova S, Bualert L, Tan-Ariya P, Siripattanapipong S, Mungthin $\mathrm{M}$, et al. Prevalence and risk factors associated with Leishmania infection in Trang Province, southern Thailand. PLoS Negl Trop Dis. 2017;11:e0006095.

34. Kumar S, Stecher G, Tamura K. MEGA7: Molecular Evolutionary Genetics Analysis version 7.0 for bigger datasets. Mol Biol Evol. 2016;33:1870-4.

35. Kongkaew W, Siriarayaporn P, Leelayoova S, Supparatpinyo K, Areechokchai D, Duang-ngern $P$, et al. Autochthonous visceral leishmaniasis: a report of a second case in Thailand. Southeast Asian J Trop Med Public Health. 2007;38:8-12.

36. Sukmee T, Siripattanapipong S, Mungthin M, Worapong J, Rangsin R, Samung $Y$, et al. A suspected new species of Leishmania, the causative agent of visceral leishmaniasis in a Thai patient. Int J Parasitol. 2008;38:617-22.

37. Suankratay C, Suwanpimolkul G, Wilde H, Siriyasatien P. Autochthonous visceral leishmaniasis in a human immunodeficiency virus (HIV)-infected patient: the first in Thailand and review of the literature. Am J Trop Med Hyg. 2010;82:4-8.

38. Osatakul S, Mungthin M, Siripattanapipong S, Hitakarun A, Kositnitikul R, Naaglor T, Leelayoova S. Recurrences of visceral leishmaniasis caused by Leishmania siamensis after treatment with amphotericin B in a seronegative child. Am J Trop Med Hyg. 2014;90:40-2.

39. Chusri S, Hortiwakul T, Silpapojakul K, Siriyasatien P. Consecutive cutaneous and visceral leishmaniasis manifestations involving a novel Leishmania species in two HIV patients in Thailand. Am J Trop Med Hyg. 2012;87:76-80.

40. Kattipathanapong P, Akaraphanth R, Krudsood S, Riganti M, Viriyavejakul P. The first reported case of autochthonous cutaneous leishmaniasis in Thailand. Southeast Asian J Trop Med Public Health. 2012;43:17-20.

41. Phumee A, Kraivichian K, Chusri S, Noppakun N, Vibhagool A, Sanprasert V, et al. Detection of Leishmania siamensis DNA in saliva by polymerase chain reaction. Am J Trop Med Hyg. 2013;89:899-905.

42. Noppakun N, Kraivichian K, Siriyasatien P. Disseminated dermal leishmaniasis caused by Leishmania siamensis in a systemic steroid therapy patient. Am J Trop Med Hyg. 2014;91:869-70

33. Chiewchanvit S, Tovanabutra N, Jariyapan N, Bates MD, Mahanupab P, Chuamanochan $\mathrm{M}$, et al. Chronic generalized fibrotic skin lesions from disseminated leishmaniasis caused by Leishmania martiniquensis in two HIVinfected patients from northern Thailand. British J Dermatol. 2015;173:663-70.

\section{Ready to submit your research? Choose BMC and benefit from:}

- fast, convenient online submission

- thorough peer review by experienced researchers in your field

- rapid publication on acceptance

- support for research data, including large and complex data types

- gold Open Access which fosters wider collaboration and increased citations

- maximum visibility for your research: over $100 \mathrm{M}$ website views per year

At BMC, research is always in progress.

Learn more biomedcentral.com/submissions 